\title{
Optimization of the Preparation Conditions of Sol-Gel Derived Ni-Co Oxide Films
}

\author{
Irina Serebrennikova ${ }^{\mathrm{a}, *, \mathrm{~b}}$ and Viola I. Birss ${ }^{\mathrm{a}, *, \mathrm{z}}$ \\ ${ }^{a}$ Department of Chemistry, University of Calgary, Calgary, Alberta, Canada T2N 1N4
}

In this work, sol-gel (SG) oxide films were formed by dip-coating Pt substrates from $\mathrm{Ni}$, Co, and mixed Ni-Co sols. After withdrawing the substrate at a constant rate, the films were dried between 100 and $400^{\circ} \mathrm{C}$ for various periods of time $(15 \mathrm{~min}$ to $1 \mathrm{~h}$ ). Based primarily on the cyclic voltammetric behavior of the SG-formed Ni-Co films after drying at high temperatures, it is suggested that both the $\mathrm{Ni}$ and $\mathrm{Co}$ sites undergo redox reactions in $1 \mathrm{M} \mathrm{NaOH}$ solutions. This also explains the high charge efficiency and charge density of SG-derived, Co-containing Ni oxide films. Careful optimization of the experimental variables in the SG film preparation route indicated that the use of 50:50 Ni-Co sols, a withdrawal rate of $6 \mathrm{~cm} / \mathrm{min}$, and drying at $250^{\circ} \mathrm{C}$ for $1 \mathrm{~h}$ yields films which display the highest charge density, the most rapid redox kinetics, and good stability to prolonged potential cycling. In addition, the charge capacity of the optimized 50:50 Ni-Co SG oxide films can be increased further by the deposition of multilayers. The redox kinetics of the optimized coatings in $1 \mathrm{M} \mathrm{NaOH}$ solution were superior to those for Ni-Co oxide films of comparable charges, but formed in other ways. Diminished reaction rates resulted when higher film drying temperatures were used (denser films) and when thicker, multilayered films were formed.

(c) 2000 The Electrochemical Society. S0013-4651(00)03-130-X. All rights reserved.

Manuscript submitted March 29, 2000; revised manuscript received June 26, 2000.

The structural and electrochemical properties of $\mathrm{Ni}, \mathrm{Co}$, and mixed Ni-Co oxides have been extensively studied due to their numerous applications in batteries ${ }^{1}$ and electrochromic devices, ${ }^{2}$ and as promising catalysts for oxygen evolution reactions (OERs) ${ }^{3}$ and oxygen reduction reactions. ${ }^{4} \mathrm{Ni}$ and Co oxide/hydroxide films can be prepared by the anodic oxidation of metallic Ni (Co) substrates, ${ }^{5}$ electron-beam evaporation, ${ }^{6}$ and electrodeposition ${ }^{7}$ methods. Chemical deposition, ${ }^{8}$ electrodeposition, ${ }^{9}$ and spray pyrolysis ${ }^{10}$ methods have been utilized to produce mixed Ni-Co oxide films, which can also be formed by the anodic oxidation of polycrystalline and amorphous Ni-Co alloys. ${ }^{11}$

Since the 1980s, the sol-gel (SG) technique has been of increasing interest to the electrochemical community as a convenient method of mixing different oxides en route to the production of amorphous and crystalline xerogels, aerogels, and conductive hydrous gels. ${ }^{12}$ The applications include modified electrodes, ${ }^{13}$ electrochromic devices, ${ }^{14}$ and corrosion protection coatings. ${ }^{15}$ In the last few years, the SG synthesis of Ni and Co oxide materials has drawn considerable interest. ${ }^{16-29}$ As an example, Svegl et al. formed spineltype $\mathrm{Co}_{3} \mathrm{O}_{4}, \mathrm{Co}(\mathrm{Al})$, and $\mathrm{Co}(\mathrm{Al}, \mathrm{Si})$-oxide films by the $\mathrm{SG}$ route and established their electrochromic properties during cycling in an aqueous alkaline $0.1 \mathrm{M} \mathrm{LiOH}$ solution. ${ }^{21,25,29}$ Chang et al. ${ }^{26}$ studied $\mathrm{Li}_{x} \mathrm{Co}_{y} \mathrm{Ni}_{1-y} \mathrm{O}_{2}$ electrodes $(y=0.1-1)$, synthesized by the citrate SG method. These SG films, having a layered structure and an average particle size of $c a .5 \mu \mathrm{m}$, were evaluated as cathode materials in lithium secondary batteries in $1 \mathrm{M} \mathrm{LiClO}_{4}$-propylene carbonate.

Our work has focused on determining the electrochemical and structural properties of SG-derived Ni, Co, and Ni-Co oxide films by using a wide variety of electrochemical and surface analytical techniques. ${ }^{16,30,31}$ One of the primary goals of this study was to prepare Ni-Co oxide films which combine high charge capacity, rapid kinetics, and stability to cycling by careful selection of the experimental variables employed in the SG preparation route. These variables include the withdrawal rate of the substrate from the coating solution, the temperature and time of drying of the SG film, the oxide composition, and the number of coatings applied on the same substrate.

This paper focuses initially on establishing the impact of the substrate withdrawal rate and drying temperature on the charge capacity of the Ni-Co SG oxide films. Also, the SG film composition (i.e., the Co content) yielding the highest charge efficiency and charge

\footnotetext{
* Electrochemical Society Active Member.

${ }^{\mathrm{b}}$ Present address: Department of Chemistry, University of Utah, Salt Lake City, Utah 84112, USA.

z E-mail: birss@ucalgary.ca
}

density has been established by cyclic voltammetry (CV) and inductively coupled plasma (ICP) spectroscopic solution analysis. By employing optimal SG film preparation conditions (e.g., composition, withdrawal rate, and drying temperature/time), multilayered SG films were also formed. Finally, the kinetics of the Ni-Co oxide redox reactions during potential cycling of these optimized films have been studied in $1 \mathrm{M} \mathrm{NaOH}$ solutions.

\section{Experimental}

$S G$ film formation.- $\mathrm{Ni}$, Co, and mixed Ni-Co sols were prepared as described elsewhere. ${ }^{16,32}$ The SG oxide films were formed by dip-coating Pt foil substrates $\left(0.3-0.8 \mathrm{~cm}^{2}\right.$ apparent area) at a constant withdrawal rate of $1-60 \mathrm{~cm} / \mathrm{min}$ and drying at temperatures between 100 and $400^{\circ} \mathrm{C}$ for various periods of time (from $15 \mathrm{~min}$ to $1 \mathrm{~h}$ ). The SG films were equilibrated by soaking in $1 \mathrm{M} \mathrm{NaOH}$ overnight prior to the onset of electrochemical measurements. ${ }^{16}$

Electrochemical experiments. - The electrochemical behavior of the SG oxide films was studied using $\mathrm{CV}$ in $1 \mathrm{M} \mathrm{NaOH}$ solution. A high area Pt mesh electrode served as the counter electrode, and a reversible hydrogen electrode (RHE) was generally employed as the reference electrode in this work. All electrochemical experiments were carried out using an EG\&G PARC 173 potentiostat/galvanostat, coupled with an EG\&G 175 programmer, while the CV responses were plotted on a Hewlett-Packard 7044B X/Y recorder.

The cell solutions were deoxygenated by purging with nitrogen before each experiment and then by passing it over the solution for the duration of the experiment. All chemicals used in this work were ACS analytical grade, and all solutions were made with triply distilled water. All experiments were carried out at room temperature, $22 \pm 1^{\circ} \mathrm{C}$.

Determination of charge efficiency of SG oxide films.-The charge efficiency of the SG oxide films was determined by combining the $\mathrm{CV}$ data with the subsequent analysis of the metal content of the film, after dissolution, by ICP-atomic emission spectroscopy (AES). For the ICP studies, SG oxide films of a range of different compositions were formed on Pt foil substrates $\left(0.3-0.7 \mathrm{~cm}^{2}\right)$, employing a withdrawal rate of $6 \mathrm{~cm} / \mathrm{min}$ and drying at $200^{\circ} \mathrm{C}$ for $15 \mathrm{~min}$. The equilibrium cathodic charge densities were determined by integrating the slow sweep rate cyclic voltammograms between 1.55 and $1.0 \mathrm{~V} v s$. RHE. Following this, the SG oxide films were stripped from the Pt substrates by sonicating in $2.5 \mathrm{~mL}$ of $0.1 \mathrm{M}$ $\mathrm{HNO}_{3}$ overnight. The volume of the sample solutions was then brought to $25 \mathrm{~mL}$ with distilled water. $1000 \mathrm{ppm}$ ICP grade solutions of $\mathrm{Ni}$ and Co (Ultra Scientific) were used to prepare the $40 \mathrm{ppm} \mathrm{Ni}$ 
and Co standards used for calibration. The analysis of the $\mathrm{Ni}$ and Co content of the sample solutions was performed (using emission lines at $216.5 \mathrm{~nm}$ for $\mathrm{Ni}$ and $228.6 \mathrm{~nm}$ for Co) on a Thermo Jarrel-Ash AtomScan 16 ICP-AES spectrometer.

Determination of SG film thickness by scanning electron microscopy (SEM) and ellipsometry.-A Hitachi 100 scanning electron microscope (Health Sciences Center, University of Calgary) was employed for the SEM work. An accelerating voltage of $20 \mathrm{kV}$ and a typical working distance of $15 \mathrm{~mm}$ were generally employed. A standard sample (2160 lines/mm) was used for accurate dimensional measurements by SEM. The SG-coated Pt foil substrates employed in the SEM studies were bent mechanically to fracture the SG films, enabling film thickness determination. The samples were attached to Al stubs using conducting carbon tape (E. T. Enterprises). Before being placed in the chamber, samples were sputter-coated with a $c a .30 \mathrm{~nm}$ thick $\mathrm{Au} / \mathrm{Pd}$ film to reduce charging effects during the SEM examination.

A Gaertner Scientific Corp. ellipsometer (model L116C) was employed to obtain the film thickness of various SG oxide films, dip-coated on Ti/Pt sputtered glass slides. The ellipsometer was interfaced to an IBM 386 PC, driven by Standard Program software (Gaertner Scientific). The ellipsometric data was acquired using a red laser beam of $632.8 \mathrm{~nm}$, an angle of incidence of $70^{\circ}$, and a polarizer angle of $45^{\circ}$. The data acquisition time was $2 \mathrm{~s}$.

\section{Results and Discussion}

Effect of SG film composition on film properties.-General $\mathrm{CV}$ behavior of $\mathrm{SG}$-formed $\mathrm{Ni}, \mathrm{Co}$, and mixed $\mathrm{Ni}$-Co oxide films.-Figure 1 shows a set of cyclic voltammograms for SG oxide films having a range of compositions, but formed using identical withdrawal rates $(6 \mathrm{~cm} / \mathrm{min})$ and drying temperatures/times $\left(200^{\circ} \mathrm{C}\right.$ for $\left.15 \mathrm{~min}\right)$. The cyclic voltammogram of the pure Ni SG oxide film displays a single pair of peaks, centered at $c a .1 .35 \mathrm{~V} v s$. RHE, characteristic of

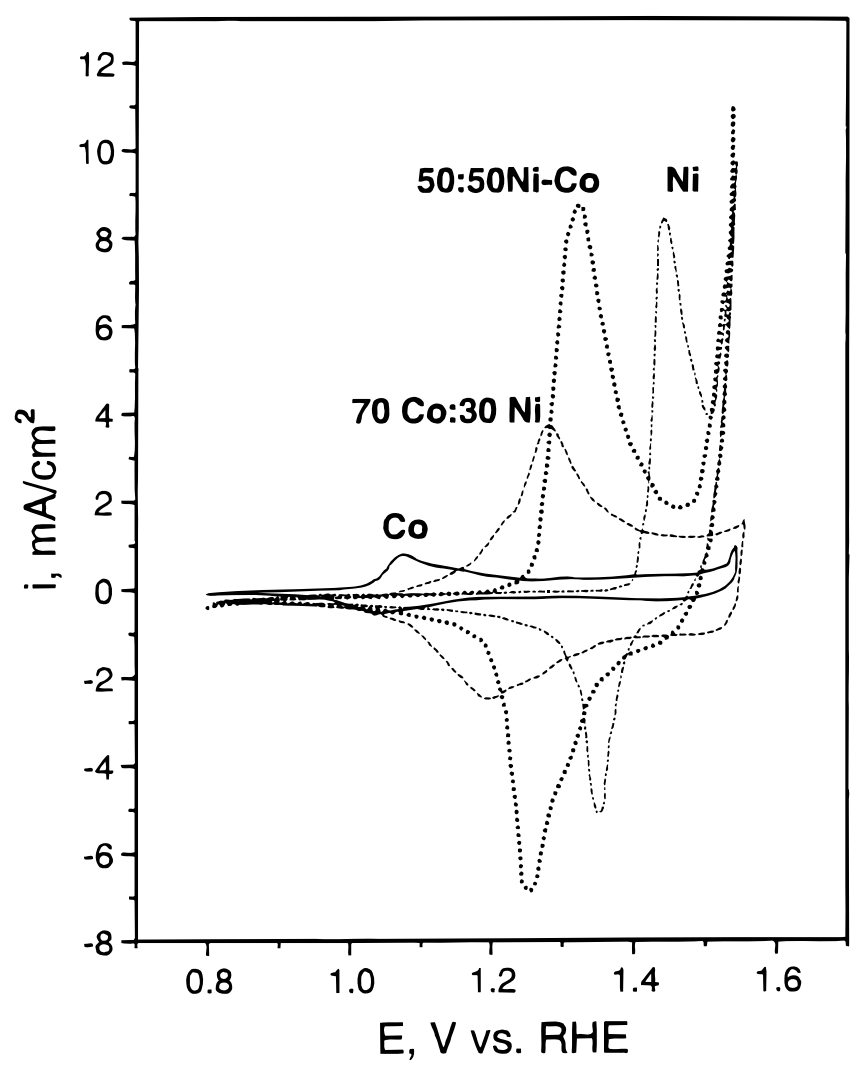

Figure 1. Cyclic voltammograms $(20 \mathrm{mV} / \mathrm{s})$ of $\mathrm{SG}$ oxide films of various compositions in $1 \mathrm{M} \mathrm{NaOH}$. Films formed at a withdrawal rate of $6 \mathrm{~cm} / \mathrm{min}$ and dried at $200^{\circ} \mathrm{C}$ for $15 \mathrm{~min}$. the $\mathrm{Ni}$ (II)/(III) redox transition, which can be described in a simplified form by the following equation 6

$$
\mathrm{Ni}(\mathrm{OH})_{2}+\mathrm{OH}^{-} \leftrightarrow \mathrm{NiOOH}+\mathrm{H}_{2} \mathrm{O}+\mathrm{e}^{-}
$$

This reaction constitutes the basis for the operation of the Ni oxide electrode in rechargeable battery applications. The large anodic current observed at potentials positive of the $\mathrm{Ni}(\mathrm{II}) /(\mathrm{III})$ redox peak reflects the onset of the OER.

The cyclic voltammogram of the pure Co SG oxide film shows a pair of peaks at $c a$. 1.05-1.1 V (Fig. 1), attributed to the $\mathrm{Co}(\mathrm{II}) /(\mathrm{III})$ reaction. ${ }^{33}$ At more positive potentials, $\mathrm{Co}(\mathrm{III})$ is oxidized further to Co(IV). ${ }^{34}$ The relatively low charges observed for pure Co oxide films, formed using identical conditions to the $\mathrm{Ni}$ oxide films, indicate that the SG-prepared Co oxide materials have fewer active sites. This could arise from the larger crystallite size (and hence lower surface area) of the Co SG oxide films, as determined from field emission SEM and transmission electron microscopy (TEM) studies. ${ }^{30}$

The hydrated 50:50 Ni-Co SG oxide films exhibit a unique electrochemical response (Fig. 1). Despite the presence of both Ni and Co in the film, the peaks characteristic of pure $\mathrm{Ni}$ and pure Co oxide are absent, and only a single pair of peaks is observed. The equilibrium potential of the mixed Ni-Co oxide film is shifted negatively $v s$. that of pure $\mathrm{Ni}$, more so as the Co content is increased. The observed single pair of $\mathrm{CV}$ peaks and the absence of voltammetric features associated with the $\mathrm{Co}(\mathrm{II}) /(\mathrm{III})$ couple (Fig. 1) are in agreement with the reported electrochemical behavior of hydrous $\mathrm{Ni}-\mathrm{Co}$ oxide films, formed by coprecipitation and electrodeposition methods. ${ }^{35,36}$ Based on parallel $\mathrm{pH}$ dependence studies, the proposed stoichiometry of the redox process for the 50:50 Ni-Co SG oxide film investigated in this work can be represented by the following reaction, ignoring water injection/expulsion during film reduction/oxidation, respectively ${ }^{30}$

$$
\begin{aligned}
\mathrm{Ni}(\mathrm{Co})^{+2} \text { oxide }+1.45 \mathrm{OH}^{-}+0.45 \mathrm{Na}^{+} \\
\leftrightarrow \mathrm{Ni}(\mathrm{Co})^{+3}\left(1.45 \mathrm{OH}^{-}\right)\left(0.45 \mathrm{Na}^{+}\right)+\mathrm{e}^{-}
\end{aligned}
$$

The addition of Co to Ni oxide electrodes is beneficial. The suggested effects include reduced mechanical stress during charge/discharge of the $\mathrm{Ni}$ oxide electrode, thus preventing electrode failure, ${ }^{37}$ as well as better utilization of the Ni sites, attributed to increased film conductivity. ${ }^{38}$ It has also been suggested that Co inhibits the formation of $\gamma-\mathrm{NiOOH},{ }^{37}$ a phase which is more difficult to reduce upon discharge than the $\beta-\mathrm{NiOOH}$ phase. These beneficial effects of $\mathrm{Co}$ are obtained, regardless of whether Co is coprecipitated with $\mathrm{Ni}$ hydroxide or is added by the surface treatment of $\mathrm{Ni}(\mathrm{OH})_{2}$ in a Co salt solution, or if $\mathrm{Ni}$ and $\mathrm{Co}$ hydroxides are mixed together. ${ }^{1}$

The absence of the characteristic Co peaks in the mixed Ni-Co oxide films strengthens the conviction of many researchers that only $\mathrm{Ni}$ is electrochemically active in these film materials. ${ }^{38}$ Recent extended X-ray absorption fine structure (EXAFS) studies of electrochemically deposited Ni hydroxides containing $10 \% \mathrm{Co}$, carried out by Kim et al., ${ }^{36}$ suggested that the oxidation state of Co does not change during potential cycling of the Ni-Co oxide electrode. The conclusion of this work was that Co does not participate in the electrochemical reaction. However, our work (Fig. 1) demonstrates the significant influence of the Co content on the shape and position of the CV peaks for the SG-formed oxide films under study. Also, a pronounced increase in the total charge density of films containing the same amount of $\mathrm{Ni}$, but with increasing Co content (see the section on Charge efficiency at SG Ni-Co oxide films formed at $200^{\circ} \mathrm{C}$ ), has been observed. Our experiments were carried out to provide further insight into the role of $\mathrm{Co}$ in the electrochemical behavior of Co-containing Ni oxide electrodes, as well as to further optimize the available charge capacity from these SG-formed materials.

Charge efficiency of $\mathrm{SG} \mathrm{Ni-Co}$ oxide films formed at $200^{\circ} \mathrm{C}$.- To establish the impact of the presence of Co on the Ni-Co $\mathrm{CV}$ response and to determine if $\mathrm{Co}$ is electrochemically active, the maximum film charge density was correlated with the complete Co and $\mathrm{Ni}$ content in the films, using CV and ICP methods (Table I). The experimental 
Table I. Charge efficiency of SG-formed Ni-Co oxide films in $1 \mathrm{M} \mathrm{NaOH}$.
$\mathrm{Ni}^{\mathrm{a}}\left(\mu \mathrm{g} / \mathrm{cm}^{2}\right)$
$\mathrm{Co}^{\mathrm{a}}\left(\mu \mathrm{g} / \mathrm{cm}^{2}\right)$
$q_{\exp }\left(\mathrm{mC} / \mathrm{cm}^{2}, 1.0-1.55 \mathrm{~V}\right)$
Efficiency $^{\mathrm{b}}$
$\left(q_{\text {exp }} / q_{\text {theor }}, \%\right)$

$\begin{array}{ll}25 & - \\ 9.3 & - \\ 16.4 & - \\ 23 & - \\ & \\ 20.5 & 1.84 \\ 18.4 & 1.63 \\ 21.8 & 1.87 \\ & \\ 21.6 & 6.6 \\ 14.5 & 4.6 \\ 17.9 & 5.2 \\ & \\ 18.3 & 15.8 \\ 24.6 & 19.3 \\ 18.9 & 14.8 \\ & \\ - & 15.4 \\ - & 15.8 \\ - & 15.1\end{array}$

$\begin{array}{cr}\text { Pure Ni oxide } & \\ 21 & 50 \\ 9 & 56 \\ 14 & 51 \\ 23 & 59 \\ 90 \mathrm{Ni}-10 \mathrm{Co} & \\ 25 & 75 \\ 28 & 92 \\ 14 & 39 \\ 70 \mathrm{Ni}-30 \mathrm{Co} & \\ 35 & 98 \\ 26 & 107 \\ 25 & 86 \\ 50: 50 \mathrm{Ni}-\mathrm{Co} & \\ 37 & 121 \\ 44 & 109 \\ 30 & 96 \\ \text { Pure Co } & \\ 2.2 & 5 \\ 4.5 & 9 \\ 3.4 & 7\end{array}$

${ }^{a}$ From ICP analysis of solutions after complete film dissolution in nitric acid.

${ }^{\mathrm{b}}$ Assuming that only $\mathrm{Ni}$ sites participate in one-electron $\mathrm{Ni}^{+2 \mid+3}$ reaction.

charge densities (from the CVs) were obtained (Table I) by integrating the slow sweep cyclic voltammograms. Following this, coatings were stripped, and the amount of $\mathrm{Ni}$ and $\mathrm{Co}$ in the film was determined (Table I) using ICP. Then the theoretical charge density of both pure $\mathrm{Ni}$ and a range of Ni-Co SG oxide films was calculated, assuming that only $\mathrm{Ni}$ is electrochemically active $\mathrm{e}^{36}$ and that each $\mathrm{Ni}$ atom contributes only one electron, ${ }^{36,39}$ due to the $\mathrm{Ni}(\mathrm{III}) /(\mathrm{II})$ redox reaction, in the potential range studied (up to $1.55 \mathrm{~V}$ ). In the pure Co SG oxide films, a 2 electron per Co site ratio was used to account for the $\mathrm{Co}(\mathrm{IV}) /(\mathrm{III})$ and $\mathrm{Co}(\mathrm{III}) /(\mathrm{II})$ transitions which are believed to occur ${ }^{34}$ over the potential range shown in Fig. 1. Taking the ratio of the observed charge density (from the cyclic voltammograms) to the theoretical one (from the ICP data), the experimental charge efficiency was calculated for each of the SG oxide films under study (Table I).

The experimental charge efficiency (Table I) for pure Ni oxide films was only $50-60 \%$. This may indicate that not all of the SG oxide nanocrystalline particles are in good electrical contact with each other and/or the Pt substrate. For pure Co oxide films, a much smaller fraction of the sites, 5-9\%, is electrochemically active. These results for pure $\mathrm{Ni}$ and pure Co oxide films are consistent with the relative magnitude of their CV signals (Fig. 1). It is also seen in Table I that the addition of $10 \%$ Co to $\mathrm{Ni}$ oxide notably increases the charge efficiency, while for a Co content of 30 and $50 \%$, the apparent charge efficiency increases further and, in some cases, exceeds $100 \%$.

There are two possible explanations for the observations in Table I for Co contents of $30 \%$ or higher. First, some Ni sites may contribute more than one electron in a potential scan to $1.55 \mathrm{~V} v s$. RHE. The formation of $\mathrm{Ni}(\mathrm{IV})$ at positive potentials has been proposed by several authors. ${ }^{39,40}$ Mansour et al. ${ }^{40}$ suggested that, during the oxidation/reduction of $\mathrm{Ni}$ oxide electrodes, the Ni sites can convert between the +2 and +4 oxidation states. Further, it has been proposed that the formation of $\mathrm{Ni}(\mathrm{IV})$ and the better utilization of the $\mathrm{Ni}$ sites may be enhanced in the presence of $\mathrm{Co}$, which is claimed to increase the conductivity of the Ni oxide films. ${ }^{38}$ However, O'Grady et al., ${ }^{39}$ although supporting the formation of $\mathrm{Ni}(\mathrm{IV})$ species, suggested that only one electron per $\mathrm{Ni}$ site is exchanged during the charge/discharge of the Ni oxide electrode. EXAFS studies of freshly prepared $\mathrm{Ni}(\mathrm{OH})_{2}$ electrodes, carried out by $\mathrm{Hu}$ et al.,${ }^{41}$ did not support the existence of $\mathrm{Ni}$ sites with a formal oxidation state higher than +3 .
Another explanation for the $>100 \%$ charge efficiency observed with some of the Ni-Co SG oxide films (Table I) is the participation of the Co sites in the redox reaction. The fact that the charge efficiency of the Ni SG oxide films under study increases by a factor of $c a$. 2 when the amount of Co equals that of $\mathrm{Ni}$ in the film strongly suggests that both metals, $\mathrm{Ni}$ and $\mathrm{Co}$, are electrochemically active in these SG-formed films. This explains the pronounced increase in the charge density of Ni SG oxide films on the addition of Co. To test the hypothesis that the Co sites are also active in these films, the CV behavior of films formed by drying at higher temperatures was examined in more detail (see the section on Electrochemical Response of Ni-Co Oxide Films Formed at 300 and $400^{\circ} \mathrm{C}$ ).

It is notable that there is a significant scatter in the efficiencies reported in Table I. This reflects the inherent irreproducibility of SG oxide film formation methods encountered and reported previously by many research groups. ${ }^{42}$

Electrochemical response of $\mathrm{Ni}$-Co oxide films formed at 300 and $400^{\circ} \mathrm{C}$. - The overall qualitative similarity of the $\mathrm{CV}$ signatures of pure $\mathrm{Ni}$ and mixed $\mathrm{Ni}-\mathrm{Co} \mathrm{SG}$ oxide films, together with the absence of the characteristic Co oxide peaks, has persuaded many researchers that, in Co-doped Ni oxides, all the charge arises from $\mathrm{Ni}$ electrochemistry alone. ${ }^{43}$ While SG oxide films formed at temperatures below $300^{\circ} \mathrm{C}$ (Fig. 1) show a single pair of peaks, similar to the data reported in the literature for hydrous $\mathrm{Ni}$-Co oxides formed by other techniques, ${ }^{35}$ the electrochemical response of SG-formed NiCo oxides formed by drying at higher temperatures $\left(300\right.$ and $\left.400^{\circ} \mathrm{C}\right)$ is different.

Figure 2 (top) shows a set of cyclic voltammograms for a 50:50 NiCo oxide film, formed on a Pt foil substrate and heated at $300^{\circ} \mathrm{C}$ for $15 \mathrm{~min}$, with time of cycling in $1 \mathrm{M} \mathrm{NaOH}$. In addition to the normally observed peaks, $A_{1} / C_{1}$, the cyclic voltammogram of a freshly formed oxide film displays an extra pair of peaks at $c a$. $1.0 \mathrm{~V}$, involving a sharp anodic peak, $\mathrm{A}_{2}$, and a broad cathodic peak, $\mathrm{C}_{2}$. With cycling time, both the $\mathrm{A}_{2}$ and $\mathrm{C}_{2}$ peaks shift to more positive potentials, merging with the main peaks, $A_{1} / C_{1}$. The charge in the main pair of peaks, $A_{1} / C_{1}$, increases proportionally, suggesting that the species initially oxidized/reduced in $\mathrm{A}_{2} / \mathrm{C}_{2}$ later undergo their redox transitions in the main pair of peaks, $A_{1} / C_{1}$. With longer cycling times, the new peaks, $\mathrm{A}_{2} / \mathrm{C}_{2}$, disappear completely and only the $\mathrm{A}_{1} / \mathrm{C}_{1}$ peaks remain. 
Peaks $A_{2} / C_{2}$ do not arise from organic residues retained in the oxide film from the SG formation step, as they are not seen for pure $\mathrm{Ni}$ oxide films, formed identically. The equilibrium potential of the $\mathrm{A}_{2} / \mathrm{C}_{2}$ peaks closely matches the potential for the $\mathrm{Co}(\mathrm{II}) /(\mathrm{III})$ redox
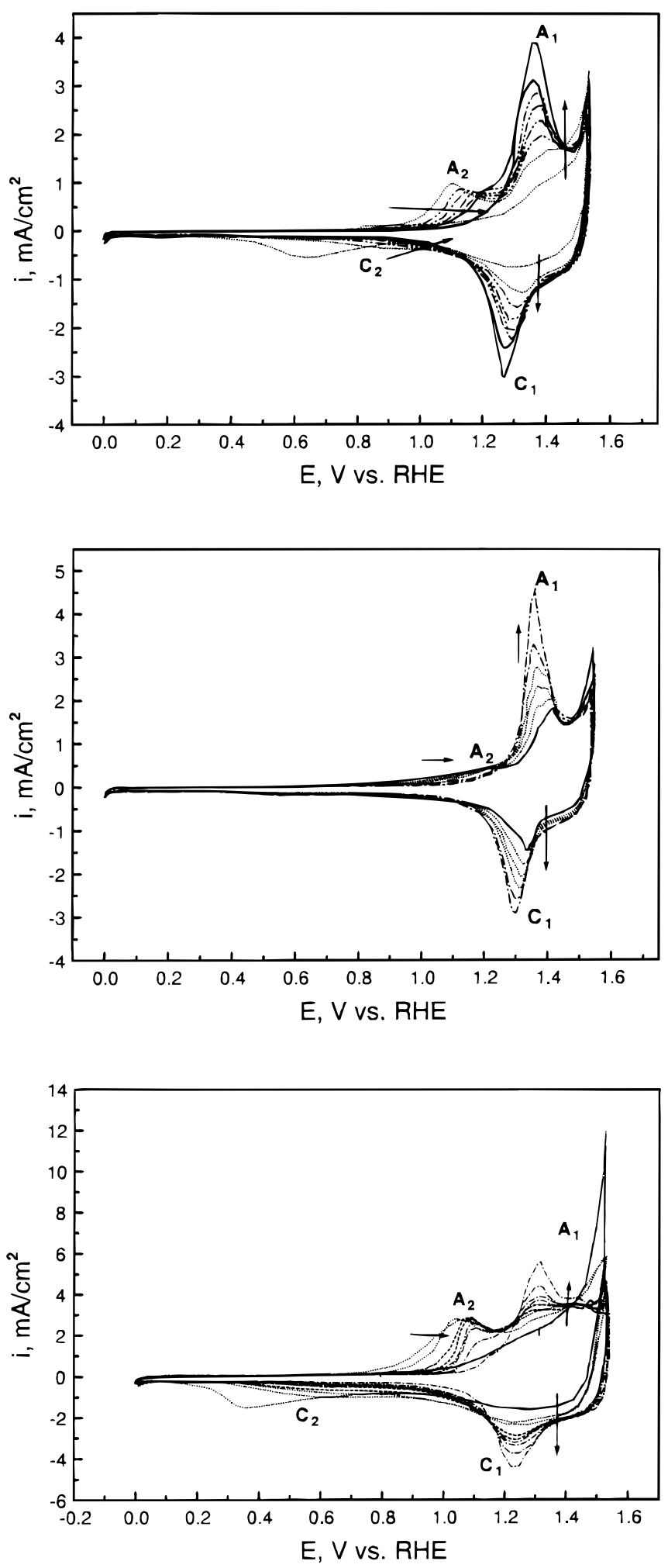

Figure 2. CV response of SG oxide films with different compositions (top) 50:50 Ni-Co, (center) 70:30 Ni-Co, and (bottom) 30:70 Ni-Co. Films were dip-coated on Pt foils $\left(0.4-0.8 \mathrm{~cm}^{2}\right)$ at a withdrawal rate of $6 \mathrm{~cm} / \mathrm{min}$ and dried at $300^{\circ} \mathrm{C}$ for $15 \mathrm{~min}$. Cyclic voltammograms recorded in $1 \mathrm{M} \mathrm{NaOH}$ at $20 \mathrm{mV} / \mathrm{s}$ (top, center) and $50 \mathrm{mV} / \mathrm{s}$ (bottom). reaction (see Fig. 1). Also, the resolution of peaks $A_{2} / C_{2}$ is clearly linked to the Co content (Fig. 2), with the peaks being largest for films containing the highest Co content, i.e., $70 \%$ Co. Further, the number of potential cycles required before the $A_{2} / C_{2}$ peaks have fully merged with peaks $A_{1} / C_{1}$ increases for films with a higher Co content (Fig. 2).

For SG-derived Ni-Co oxide films, formed by drying at 300 and $400^{\circ} \mathrm{C}$, we suggest that the $\mathrm{A}_{2} / \mathrm{C}_{2}$ peaks, seen in the first $\mathrm{CV}$ cycles in $1 \mathrm{M} \mathrm{NaOH}$, reflect the redox reaction of the Co sites. It appears possible to initially resolve the $\mathrm{Ni}$ and Co electrochemistry separately, under these conditions. The Co sites are oxidized/reduced between their (II)/(III) states at $c a$. $1.0 \mathrm{~V}$, while the Ni sites undergo their (II)/(III) transition in the peaks at $c a .1 .35 \mathrm{~V}$. With longer times of potential cycling, the charge due to the Co electrochemistry is transferred into the $A_{1} / C_{1}$ peaks (Fig. 2 top and bottom). This strongly suggests that both $\mathrm{Ni}$ and $\mathrm{Co}$ oxide redox processes are occurring in the $A_{1} / C_{1}$ peaks, as has also been suggested for chemically precipitated mixtures of $\mathrm{Ni}(\mathrm{OH})_{2}$ and $\mathrm{Co}(\mathrm{OH})_{2} \cdot{ }^{44}$

In the present work, the appearance of the $\mathrm{A}_{2} / \mathrm{C}_{2}$ peaks in the cyclic voltammograms for SG Ni-Co oxide films formed at 300$400^{\circ} \mathrm{C}$ (Fig. 2) is clearly linked to the drying treatment. The cyclic voltammograms obtained after prolonged potential cycling of initially anhydrous Ni-Co SG oxides, formed at 300 and $400^{\circ} \mathrm{C}$, display a single pair of peaks (Fig. 2) and appear similar to the cyclic voltammograms of hydrous Ni-Co oxide films, formed by electrodeposition, ${ }^{36}$ coprecipitation, ${ }^{44}$ and, in the present work, by the SG technique at temperatures $\angle 300^{\circ} \mathrm{C}$ (Fig. 1). It is suggested that, with time of cycling (Fig. 2), the SG Ni-Co oxide films become saturated with water. This causes the redox potentials of the $\mathrm{Ni}$ and Co sites to change and the SG films to develop a single synergistic redox potential, characteristic of the mixed Ni-Co oxide material. Also, the charge in the steady-state peak is similar to the sum of the charges in the two original sets of peaks (Fig. 2), other than in the first cycle.

The electron diffraction studies of the SG-formed 50:50 Ni-Co oxide films, ${ }^{30}$ dried at various temperatures for $15 \mathrm{~min}$, indicated the presence of face-centereed cubic $\mathrm{NiO}$ and $\mathrm{CoO}$ phases. The unit cell parameters of the cubic $\mathrm{CoO}$ and $\mathrm{NiO}$ are sufficiently similar $(4.26$ and $4.18 \AA$, respectively) to permit the formation of solid solutions throughout the entire composition range. ${ }^{45} \mathrm{Kim}$ et al. ${ }^{36}$ suggested that coelectrodeposition of $\mathrm{Ni}$ and $\mathrm{Co}$ hydroxides generates a mixed single-phase metal hydrous oxide, in which Co ions occupy Ni sites in the lattice, and not two intermixed phases, each consisting of a single metal hydrous oxide.

It is suggested here that the formation of the SG oxides at 300 and $400^{\circ} \mathrm{C}$ may result in the partial segregation of $\mathrm{NiO}$ and $\mathrm{CoO}$ phases. Therefore, in these anhydrous films (as confirmed by IR spectroscopy results ${ }^{30}$ ), the Co and $\mathrm{Ni}$ sites may initially react at their characteristic potentials. Although a complete ternary diagram for the NiO$\mathrm{CoO}-1 / 2 \mathrm{O}_{2}$ system is not presently available, ${ }^{46}$ the coexistence of various crystalline and amorphous phases of nanosized particles (e.g., $\mathrm{NiO}, \mathrm{CoO}, \mathrm{Co}_{3} \mathrm{O}_{4}$, and $\mathrm{NiCo}_{2} \mathrm{O}_{4}$ ) in mixed $\mathrm{Ni}$-Co oxide films has been reported, ${ }^{28,47} \mathrm{In}$ addition, the existence of multiple $\mathrm{CV}$ anodic peaks during potential cycling in alkaline solutions has been reported for a number of $\mathrm{Ni}-\mathrm{Co}$ oxide materials, formed at $300-400^{\circ} \mathrm{C}$ by the thermal decomposition of $\mathrm{Co}$ and Ni nitrates. ${ }^{48,49}$

Based on these ICP and CV results, it appears likely that both the $\mathrm{Ni}$ and Co sites participate in the oxidation/reduction of SG-formed $\mathrm{Ni}$-Co oxide films, especially in films with a Co content $\geq 30 \%$. This then explains the charge efficiency of $>100 \%$ (Table I) seen for films with Co contents of 30 and $50 \%$. To further test this suggestion, in situ X-ray absorption near-edge structure and EXAFS measurements of these Ni-Co SG-formed oxides would be appropriate.

Optimization of the withdrawal rate and drying conditions during $S G$ film formation.-The rate at which a substrate is withdrawn from the SG coating solution determines the thickness of the film. The use of more rapid substrate withdrawal rates leads to thicker films and, thus, higher charge densities, indicating a greater number of electrochemically active metal sites. ${ }^{16}$ Although high charge den- 
sities are desired, it was found here that thinner films, formed at slower withdrawal rates, sustain prolonged potential cycling better, similar to the results for chemically precipitated $\mathrm{Ni}(\mathrm{OH})_{2}$ films ${ }^{50} \mathrm{~A}$ withdrawal rate of $6 \mathrm{~cm} / \mathrm{min}$ was therefore selected here, as robust SG films with relatively large charge densities then resulted.

A SEM study of our SG films ${ }^{30}$ showed that the drying temperature strongly influences their density. When the substrate is withdrawn at a constant rate from the same solution, thinner coatings are obtained with higher drying temperatures. The use of higher calcination temperatures also results in a loss of water, as was indicated by our IR spectroscopy results, ${ }^{30}$ as well as the formation of larger nanocrystallites (TEM data), as was mentioned earlier.

Table II shows the impact of the drying temperature on the equilibrium charge density of 50:50 SG oxide films, all formed using otherwise identical conditions and therefore containing the same total amount of film material. The maximum charge density is achieved when the films are dried at temperatures between 180 and $250^{\circ} \mathrm{C}$. The smaller charge densities at lower temperatures may result from a gel-like structure of the film, in which retained organic residues block access of ions to the metal sites. ${ }^{16}$ It is suggested here that drying above $180^{\circ} \mathrm{C}$ is necessary to form relatively compact SG films in which the nanocrystallite oxide particles are well interconnected, allowing electrons to freely pass between the SG film and the underlying Pt substrate. Similar behavior has been reported ${ }^{51}$ for chemically precipitated $\mathrm{Ni}(\mathrm{OH})_{2}$ films having a gel-like structure, where only the material close to the Pt substrate surface was suggested to be electroactive.

The decrease in the charge density of the SG Ni-Co oxides observed at higher temperatures (Table II) is in agreement with prior reports for $\mathrm{Ni}$ and $\mathrm{Co}$ hydroxide films formed by other methods. ${ }^{52}$ The lower charge for films prepared above $250^{\circ} \mathrm{C}$ may have several origins. These include phase transformations, the possible collapse of the oxide structure (reflected by the SG film shrinkage seen by SEM), the loss of water (confirmed by IR spectroscopy results), and/or an increasing crystallite size and, thus, a reduced total surface area of the oxide films (TEM data). ${ }^{30,31}$ Overall, the temperature employed during drying of the SG oxide films under study here has a marked effect on their electrochemical response, likely due to changes in the film microstructure and composition. The maximum charge capacity and best stability were obtained for SG oxide films which were formed between 180 and $250^{\circ} \mathrm{C}$ with the drying time increased from 15 min to $1 \mathrm{~h}$.

Formation of optimized multicoatings of Ni-Co oxide films.-The careful selection of the experimental variables in the SG preparation route indicated that the use of 50:50 Ni-Co sols, dip-coated on conducting substrates at a withdrawal rate of $6 \mathrm{~cm} / \mathrm{min}$ and dried at $250^{\circ} \mathrm{C}$ for $1 \mathrm{~h}$, yields films that display the highest charge density and the best stability to prolonged potential cycling. SG oxide films formed using these optimized conditions are further referred to as "optimized."

Table II. Impact of the drying temperature on the cathodic peak charge density of 50:50 Ni-Co SG oxide films ${ }^{\mathrm{a}}$

$$
\begin{gathered}
\text { Drying temperature } \\
\left({ }^{\circ} \mathrm{C}\right)
\end{gathered} \begin{gathered}
\text { Equilibrium cathodic peak charge } \\
\text { density }{ }^{\mathrm{b}}\left(\mathrm{mC} / \mathrm{cm}^{2}\right)
\end{gathered}
$$

$\begin{array}{rc}30 & 2 \\ 150 & 6-8 \\ 190 & 32-41 \\ 250 & 33-39 \\ 300 & 23 \\ 400 & 18\end{array}$

${ }^{\text {a }}$ All films dip-coated on Pt foils at a withdrawal rate of $24 \mathrm{~cm} / \mathrm{min}$ and dried in air for $15 \mathrm{~min}$.

${ }^{\mathrm{b}}$ Charge densities obtained from slow sweep rate cyclic voltammograms in $1 \mathrm{M} \mathrm{NaOH}$.
Another way to achieve high charge densities in SG processing is to form multiple coatings of the oxide film on the same substrate. The dip-coating and heating steps are repeated for each additional film layer, so that thicker films are gradually formed. ${ }^{17}$ The cyclic voltammograms of the optimized 50:50 Ni-Co oxide films displayed a single pair of voltammetric peaks, $\mathrm{A}_{1} / \mathrm{C}_{1}$, similar to the electrochemical response of the 50:50 Ni-Co oxide in Fig. 1. The charge capacity of the optimized Ni-Co SG oxide films increases linearly as a function of the application of three layers (Fig. 3), while the film thickness increases from $c a .65 \mathrm{~nm}$ (single coat) to $c a$. $165 \mathrm{~nm}$ (triple coat), determined by SEM and ellipsometry. ${ }^{30}$ Additional coatings could be applied if a higher charge density were desired.

Kinetics of SG-derived films. - It is of interest to compare the kinetics of 50:50 Ni-Co oxide films formed using identical withdrawal rates and displaying similar charge densities, but exposed to different drying treatments. The first film was formed from a 50:50 $\mathrm{Ni}-\mathrm{Co}$ sol and dried at $200^{\circ} \mathrm{C}$ for $15 \mathrm{~min}$. It was $c a .400 \mathrm{~nm}$ thick, and the cyclic voltammogram yielded an equilibrium charge density of $45 \mathrm{mC} / \mathrm{cm}^{2}$. Figure 4 (left) shows a plot of the cathodic peak current density as a function of the sweep rate for this particular film. ${ }^{16} \mathrm{~A}$ linear dependence of the peak current on sweep rate, $s$, is observed at slow sweep rates $(<35 \mathrm{mV} / \mathrm{s})$, consistent with the behavior of surface films such as hydrous oxides and conducting polymers. ${ }^{53}$ At sweep rates greater than this, the redox reaction becomes controlled by diffusion, as seen from the $s^{1 / 2}$ dependence of the peak current.

When a similar coating was formed using optimized conditions, i.e., the identical withdrawal rate $(6 \mathrm{~cm} / \mathrm{min})$ followed by drying at $250^{\circ} \mathrm{C}$ for $1 \mathrm{~h}$, the film thickness was reduced to $c a .65 \mathrm{~nm},{ }^{30}$ while the charge density remained unchanged at $44 \mathrm{mC} / \mathrm{cm}^{2}$. Figure 4 (right) shows that, for this $65 \mathrm{~nm}$ thick film, a linear dependence of the cathodic peak current density on sweep rate is now seen up to $100 \mathrm{mV} / \mathrm{s}$, indicating the absence of any diffusion limitations. Therefore, a single-layered optimized 50:50 Ni-Co oxide film [Fig. 4 (right)] behaves as a fully reversible surface redox system under these conditions. The more compact structure of the $65 \mathrm{~nm}$ thick film [Fig. 4 (right)] appears to inhibit the onset of diffusion limitations, as compared to the situation with the $400 \mathrm{~nm}$ film [Fig. 4 (left)]. This suggests that site-to-site electron hopping is the slow process, accelerated by bringing the $\mathrm{Co}$ and $\mathrm{Ni}$ sites closer together with more extensive film drying.

These 50:50 SG-formed Ni-Co oxide films, having a relatively high charge capacity $\left(c a .45 \mathrm{mC} / \mathrm{cm}^{2}\right)$, show excellent kinetic characteristics, especially when compared to those of similar oxide films

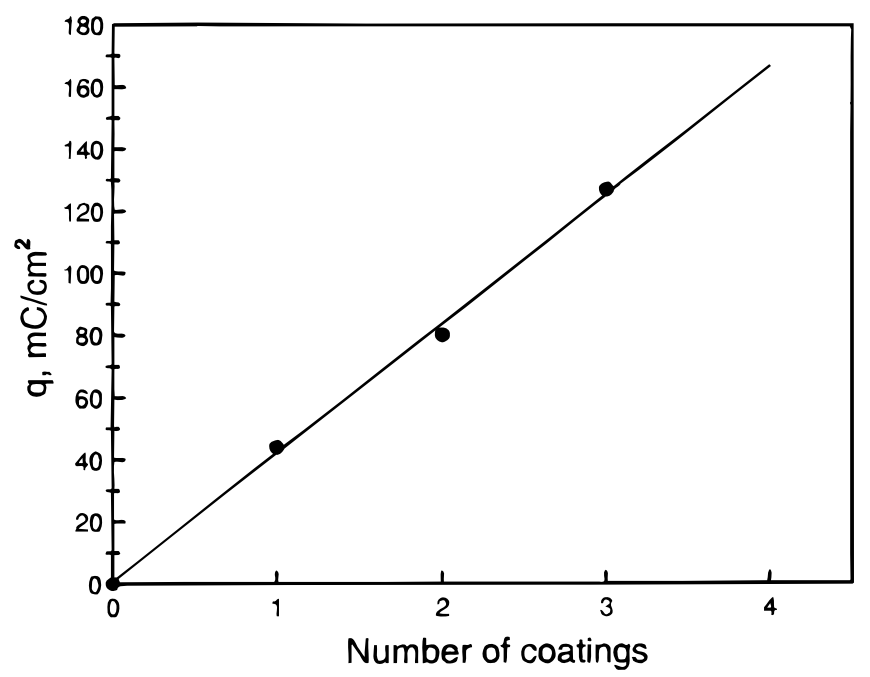

Figure 3. Equilibrium cathodic peak charge density of 50:50 Ni-Co oxide films as a function of number of layers. Each layer formed at withdrawal rate of $6 \mathrm{~cm} / \mathrm{min}$ and dried at $250^{\circ} \mathrm{C}$ for $1 \mathrm{~h}$. Films equilibrated by immersion in $1 \mathrm{M} \mathrm{NaOH}$ overnight. 


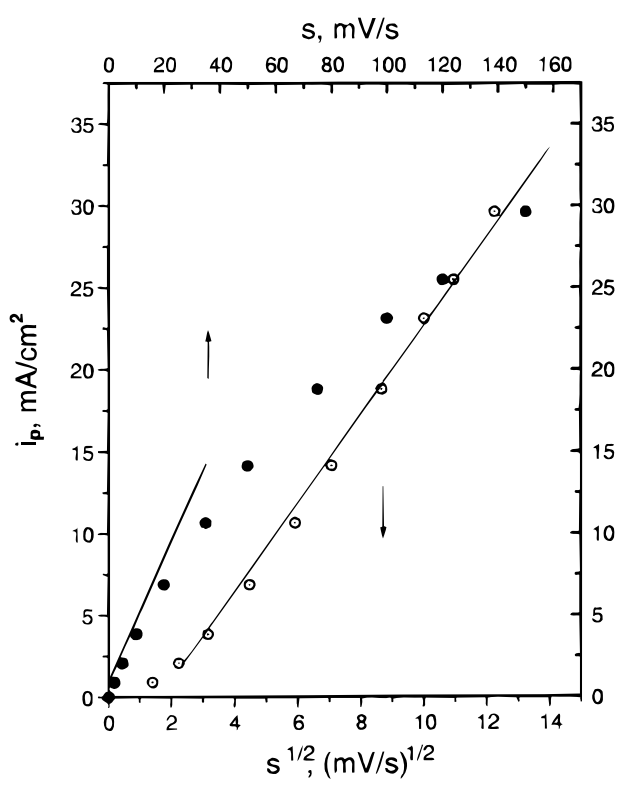

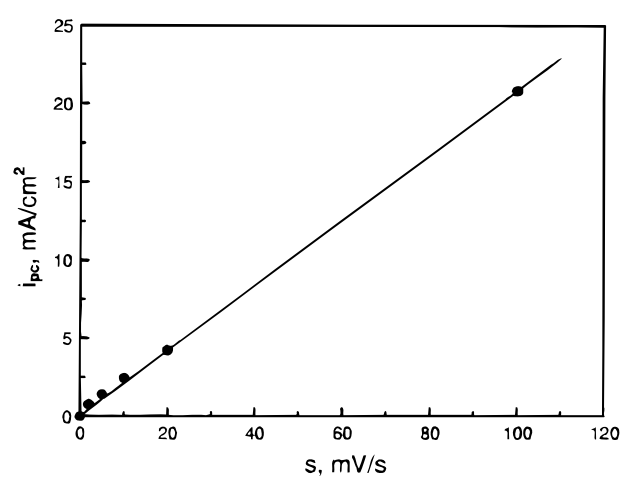

Figure 4. Dependence of the cathodic peak current density on the sweep rate for the 50:50 Ni-Co oxide films with equilibrium charge density of $c a .45 \mathrm{mC} / \mathrm{cm}^{2}$. Films dip-coated on Pt substrates at $6 \mathrm{~cm} / \mathrm{min}$ and dried at (left) $190^{\circ} \mathrm{C}$ for $15 \mathrm{~min}^{16}$ and (right) at $250^{\circ} \mathrm{C}$ for $1 \mathrm{~h}$. formed by other techniques. A linear $i_{\mathrm{p}} \propto s$ dependence is normally seen only for thin Ni-Co oxide films (up to $500 \mathrm{mV} / \mathrm{s}$ for eight monolayers of film having a charge density of $1.2 \mathrm{mC} / \mathrm{cm}^{2}$ and up to $100 \mathrm{mV} / \mathrm{s}$ for a $\mathrm{ca} .100$ monolayer thick film with a charge density of $15 \mathrm{mC} / \mathrm{cm}^{2}$ ) formed by the anodic oxidation of amorphous alloys ${ }^{54}$ or by spray pyrolysis (up to $20 \mathrm{mV} / \mathrm{s}$ for $8 \mathrm{mC} / \mathrm{cm}^{2}$ films). ${ }^{55}$ For thicker films, such a relationship is either seen only at very slow sweep rates, or a $s^{1 / 2}$ dependence, typical for mass-transport controlled reactions, is observed at all sweep rates. ${ }^{3}$

Figures 5 and 6 show the sweep rate dependence of the cathodic peak current density of the optimized double and triple layer SGformed $\mathrm{Ni}$-Co oxide films, respectively. A linear dependence is seen up to $20 \mathrm{mV} / \mathrm{s}$ for the double coating (Fig. 5) and only up to $10 \mathrm{mV} / \mathrm{s}$ (Fig. 6) for the triple coating. The onset of the diffusion-controlled conditions at slower sweep rates after the formation of a second and third SG film layer is in agreement with their increased thickness.

Thus, the SG oxides under study show fully reversible surface behavior at slow sweep rates. At more rapid sweep rates, the redox

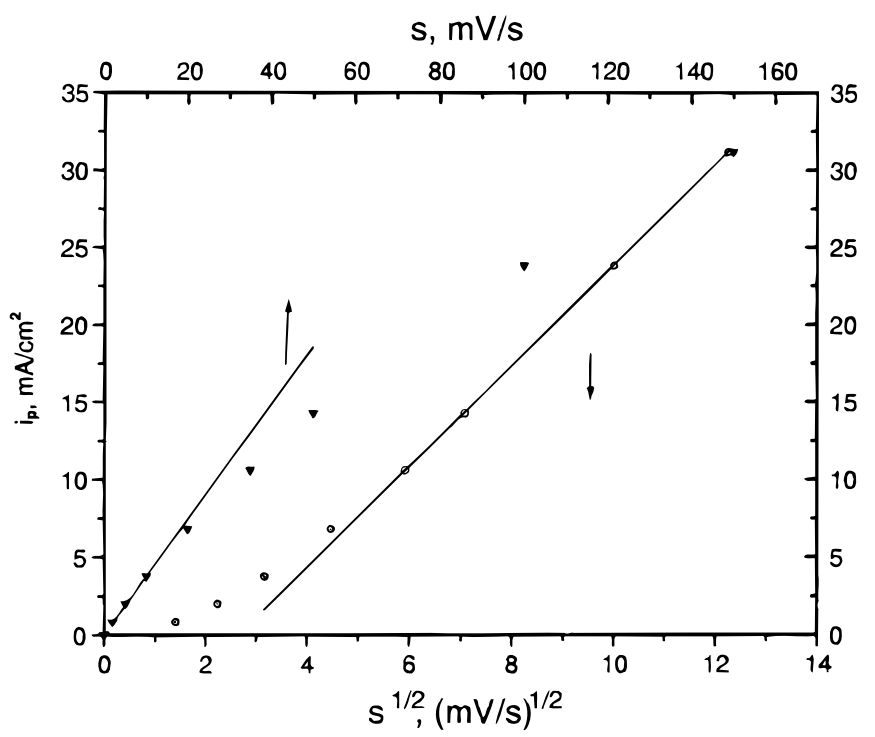

Figure 5. The effect of sweep rate on the cathodic peak current density of a 50:50 two-layered Ni-Co coating, with equilibrium charge density of $59 \mathrm{mC} / \mathrm{cm}^{2}$, in $1 \mathrm{M} \mathrm{NaOH}$. Each layer was formed on Pt substrate at $6 \mathrm{~cm} / \mathrm{min}$ and dried at $250^{\circ} \mathrm{C}$ for $1 \mathrm{~h}$. reaction becomes controlled by the transport of ions and/or solvent inside the film as reflected by the $i_{\mathrm{p}} \propto s^{1 / 2}$ dependence. During the formation of multicoatings, an increase in the film thickness after the formation of a second and third layer results in the onset of diffusion limitations at lower sweep rates.

\section{Conclusions}

In this work, SG-derived Ni-Co oxide films were formed on $\mathrm{Pt}$ substrates by dip-coating from $\mathrm{Ni}, \mathrm{Co}$, and mixed Ni-Co sols. After withdrawing the substrate at a constant rate, the films were dried at between 100 and $400^{\circ} \mathrm{C}$ for various periods of time (15 min to $1 \mathrm{~h}$ ). The $\mathrm{CV}$ response for mixed $\mathrm{Ni}-\mathrm{Co}$ films in $1 \mathrm{M} \mathrm{NaOH}$ is unique, when the films are dried at $<300^{\circ} \mathrm{C}$, and does not show the individual features of $\mathrm{Ni}$ and $\mathrm{Co}$. When dried at temperatures higher than this, the signatures of $\mathrm{Co}$ and $\mathrm{Ni}$ can be resolved separately. Based on the observed charge density, the withdrawal rate and drying temperature determine the thickness of the film; thinner films are formed at slower withdrawal rates and higher drying temperatures. The SG films under study here ranged between 60 and $800 \mathrm{~nm}$ thick.

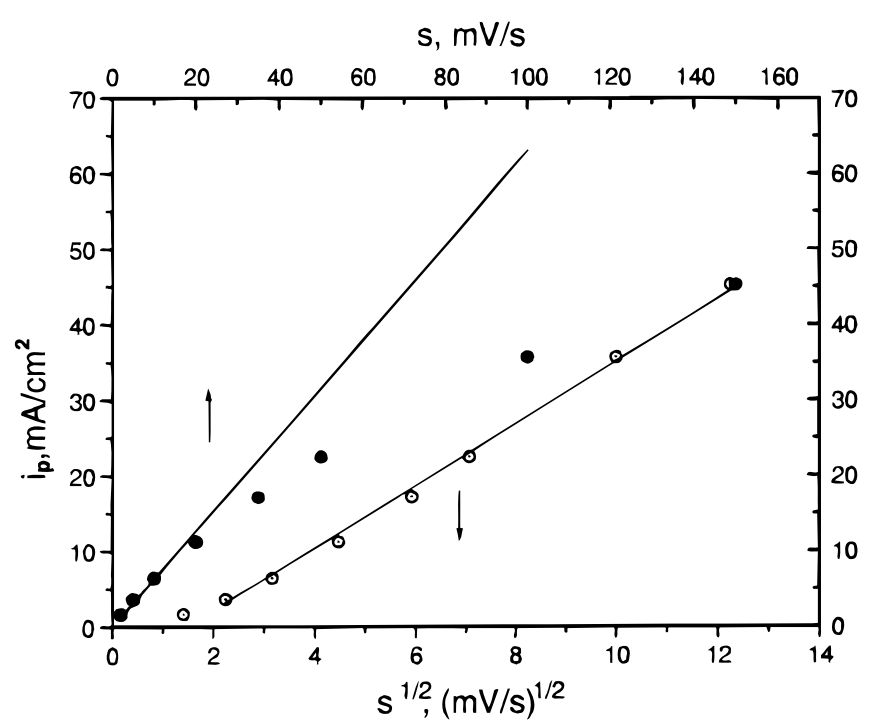

Figure 6. The effect of sweep rate on the cathodic peak current density of a three-layered 50:50 Ni-Co coating, with equilibrium charge density of $127 \mathrm{mC} / \mathrm{cm}^{2}$, in $1 \mathrm{M} \mathrm{NaOH}$. Each layer formed on Pt substrate at $6 \mathrm{~cm} / \mathrm{min}$ and dried at $250^{\circ} \mathrm{C}$ for $1 \mathrm{~h}$. 
The ICP and $\mathrm{CV}$ results, especially for films dried at above $300^{\circ} \mathrm{C}$, strongly suggest that both $\mathrm{Ni}$ and $\mathrm{Co}$ sites participate in the oxidation/reduction reaction (and contribute to the measured charge density) of the SG-formed oxides. Films dried at high temperatures, likely being dehydrated, show redox peaks reflecting the presence of both $\mathrm{Co}$ and $\mathrm{Ni}$. However, with time of cycling in $1 \mathrm{M} \mathrm{NaOH}$, the charge in the Co oxide peaks merges with that of the $\mathrm{Ni}$, with the total charge passed remaining constant. This suggests strongly that both $\mathrm{Co}$ and $\mathrm{Ni}$ contribute to the electrochemistry in the typical $\mathrm{CV}$ response seen for these films. This explains the increased charge efficiency and charge density observed when $\mathrm{Co}$ is added to the $\mathrm{Ni}$ SG oxide films.

A careful study of the experimental variables in the SG preparation route has indicated that the use of a 50:50 Ni-Co sol, dip-coating of a conducting substrate at a withdrawal rate of $6 \mathrm{~cm} / \mathrm{min}$, and drying at $250^{\circ} \mathrm{C}$ for $1 \mathrm{~h}$ yields films that display the highest charge density and demonstrate good stability to prolonged potential cycling. The charge capacity of the optimized 50:50 Ni-Co SG oxide films can be increased further by the deposition of multilayers. The sweep rate studies of the optimized 50:50 Ni-Co SG oxide films showed that these materials combine high charge density and excellent kinetics, compared to similar Ni-Co films prepared by other techniques.

\section{Acknowledgments}

Financial assistance from the Department of Chemistry (University of Calgary), the Killam Trusts, PanCanadian Petroleum Ltd., the Province of Alberta, ASC-Division of Analytical Chemistry, JIAS of Canada, and A.S.M. International "Calgary Chapter" for the scholarship support of I.S. is gratefully acknowledged. The authors thank the Natural Sciences and Engineering Research Council (NSERC) of Canada for the overall support of this research. article.

The University of Calgary assisted in meeting the publication costs of this

\section{References}

1. J. McBreen, in Modern Aspects of Electrochemistry, Vol. 21, R. White, J. Bockris, and B. Conway, Editors, Plenum Press, New York (1990).

2. T. Maruyama and S. Arai, J. Electrochem. Soc., 143, 1383 (1996)

3. I. Nikolov, R. Darkaoui, E. Zhecheva, R. Stoyanova, N. Dimitrov, and T. Vitanov, J. Electroanal. Chem., 429, 157 (1997).

4. L. C. Schumacher, I. B. Holzhueter, I. R. Hill, and M. J. Dignam, Electrochim Acta, 35, 975 (1990).

5. K. Lian, S. J. Thorpe, and D. W. Kirk, Electrochim. Acta, 37, 2029 (1992)

6. S. I. Cordoba-Torresi, A. Hugot-Le Goff, and S. Joiret, J. Electrochem. Soc., 138, 1554 (1991)

7. M. Chigane and M. Ishikawa, J. Electrochem. Soc., 141, 3439 (1994).

8. N. Krasteva, V. Fotty, and S. Armyanov, J. Electrochem. Soc., 141, 2864 (1994).

9. J. Kupka and A. Budniok, J. Appl. Electrochem., 20, 1015 (1990)

10. R.-N. Singh, M. Hamdani, J.-F. Koenig, G. Poillerat, G. L. Gautier, and P. Chartier, J. Appl. Electrochem., 20, 442 (1990).

11. K. Lian, D. W. Kirk, and S. J. Thorpe, Electrochim. Acta, 36, 537 (1991).

12. O. Lev, Z. Wu, S. Bharathi, V. Glezer, A. Modestov, J. Gun, L. Rabinovich, and S Sampath, Chem. Mater., 9, 2354 (1997).

13. U. Georgi, E. Brendler, H. Gorz, and G. Roewer, J. Sol.-Gel Sci. Technol., 8, 507 (1997).
14. G.-W. Jang, C. Chen, R. W. Gumbs, Y. Wei, and J.-M. Yeh, J. Electrochem. Soc., 143, 2591 (1996).

15. P. P. Trzskoma-Paulette and A. Nazeri, J. Electrochem. Soc., 144, 1307 (1997)

16. I. Serebrennikova and V. I. Birss, J. Electrochem. Soc., 144, 566 (1997).

17. A. Surca, B. Orel, B. Pihlar, and P. Bukovec, J. Electroanal. Chem., 408, 83 (1996).

18. A. Surca, B. Orel, and B. Pihlar, J. Sol.-Gel Sci. Technol., 8, 743 (1997).

19. K.-C. Liu and M. A. Anderson, J. Electrochem. Soc., 143, 124 (1996).

20. A. Surca, B. Orel, R. Cerc-Korosec, P. Bukovec, and B. Pihlar, J. Electroanal. Chem., 433, 57 (1997).

21. F. Svegl, B. Orel, M. G. Hutchins, and K. Kalcher, J. Electrochem. Soc., 143, 1532 (1996)

22. M. El Baydi, G. Poillerat, J.-L. Rehspringer, J. L. Gautier, J.-F. Koenig, and P. Chartier, J. Solid State Chem., 109, 281 (1994).

23. E. C. Barrera, T. G. Viveros, and U. Morales, WREC, 733 (1996)

24. G. Spinolo, S. Ardizzone, and S. Trasatti, J. Electroanal. Chem., 423, 49 (1997).

25. F. Svegl, B. Orel, and M. Hutchins, J. Sol.-Gel Sci. Technol., 8, 765 (1997).

6. S. H. Chang, S.-G. Kang, and K. H. Jang, Bull. Korean Chem. Soc., 18, 61 (1997)

27. R. Monaci, A. Musinu, G. Piccaluga, and G. Pinna, Mater. Sci. Forum, 195, 1 (1995).

28. M. El Baydi, S. K. Tiwari, R. N. Singh, J.-L. Rehspringer, P. Chartier, J. F. Koenig, and G. Poillerat, J. Solid State Chem., 116, 157 (1995).

29. F. Svegl, B. Orel, P. Bukovec, K. Kalcher, and M. G. Hutchins, J. Electroanal Chem., 418, 53 (1996).

30. I. Serebrennikova, Ph.D. Thesis, University of Calgary, Calgary, Alberta, Canada (1999)

31. I. Serebrennikova and V. I. Birss, J. Mater. Sci., Submitted.

32. F. H. Moser and N. R. Lynam, U.S. Pat. 4,959,247 (1990).

33. L. D. Burke, M. E. Lyons, and O. J. Murphy, J. Electroanal. Chem., 132, 247 (1982).

34. R. P. Simpraga, J. Electroanal. Chem., 355, 79 (1993).

35. D. A. Corrigan and R. M. Bendert, J. Electrochem. Soc., 136, 723 (1989)

36. S. Kim, D. A. Tryk, M. R. Antonio, R. Carr, and D. A. Scherson, J. Phys. Chem., 98, 10269 (1994)

37. H. H. Law and J. Sapjeta, J. Electrochem. Soc., 136, 1603 (1989).

38. M. Oshitani, H. Yufu, K. Takashima, S. Tsuji, and Y. Matsumaru, J. Electrochem. Soc., 136, 1590 (1989).

39. W. O'Grady, K. Pandya, K. Swidler, and D. Corrigan, J. Electrochem. Soc., 143, 1613 (1996).

40. A. N. Mansour, C. A. Melendres, and J. Wong, J. Electrochem. Soc., 145, 1121 (1998).

41. Y. Hu, I. T. Bae, M. R. Antonio, and D. A. Scherson, Can. J. Chem., 75, 1721 (1997).

42. D. Rolison (Naval Research Lab.), Personal communication

43. P. Nkeng, G. Poillerat, J. F. Koenig, P. Chartier, B. Lefez, J. Lopitaux, and M Lenglet, J. Electrochem. Soc., 142, 1777 (1995).

44. S. I. Cordoba, R. E. Carbonio, M. Lopez Teijelo, and V. A. Macagno, Electrochim. Acta, 31, 1321 (1986).

45. S. M. Jasem and A. C. C. Tseung, J. Electrochem. Soc., 126, 1353 (1979).

46. N. Heller-Ling, M. Prestatt, J.-L. Gautier, J.-F. Koenig, G. Poillerat, and P. Chartier, Electrochim. Acta, 42, 197 (1997).

47. Y. Roginskaya, O. Morozova, E. Lubnin, Y. Ulitina, G. Lopukhova, and S. Trasatti, Langmuir, 13, 4621 (1997).

48. C.-C. Hu, Y.-S. Lee, and T.-C. Wen, Mater. Chem. Phys., 48, 246 (1997).

49. P. Rasiyah, A. C. C. Tseung, and D. B. Hibbert, J. Electrochem. Soc., 129, 1724 (1982)

50. R. E. Carbonio, V. A. Macagno, M. C. Giordano, J. R. Vilche, and A. J. Arvia, J. Electrochem. Soc., 129, 983 (1982)

51. M. V. Vazquez, M. J. Avena, and C. P. De Pauli, Electrochim. Acta, 40, 907 (1995).

52. V. Srinivasan and J. W. Weidner, J. Electrochem. Soc., 144, L210 (1997).

53. C. R. Martin, I. Rubinstein, and A. J. Bard, J. Am. Chem. Soc., 104, 4817 (1982).

54. K. Lian and V. Birss, J. Electrochem. Soc., 138, 2885 (1991).

55. R. Singh, J.-F. Koenig, G. Poillerat, and P. Chartier, J. Electrochem. Soc., 137, 1408 (1990). 